
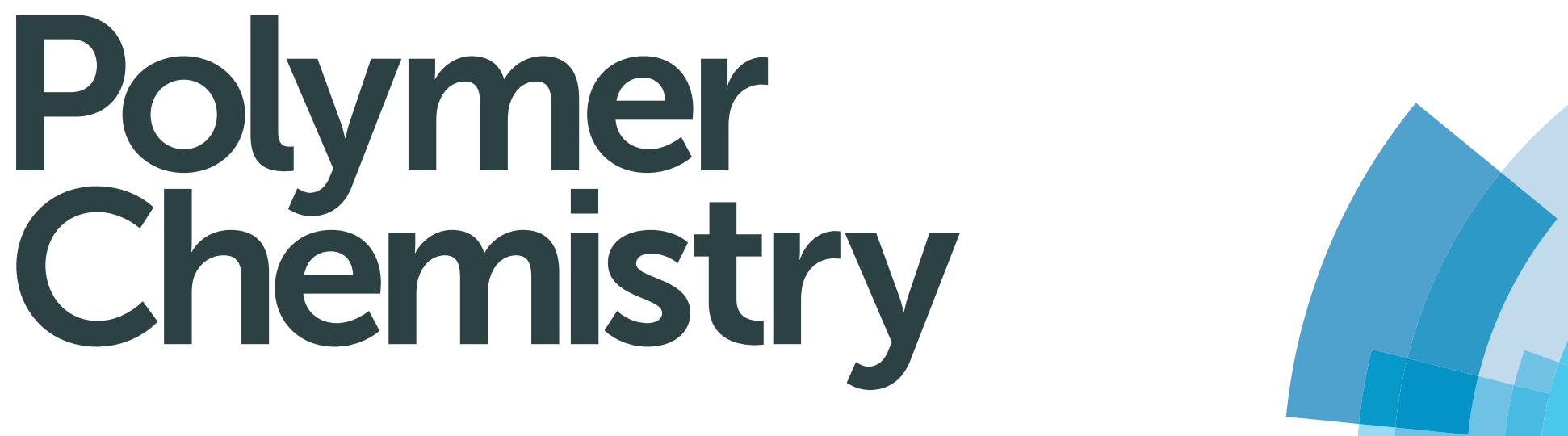

www.rsc.org/polymers

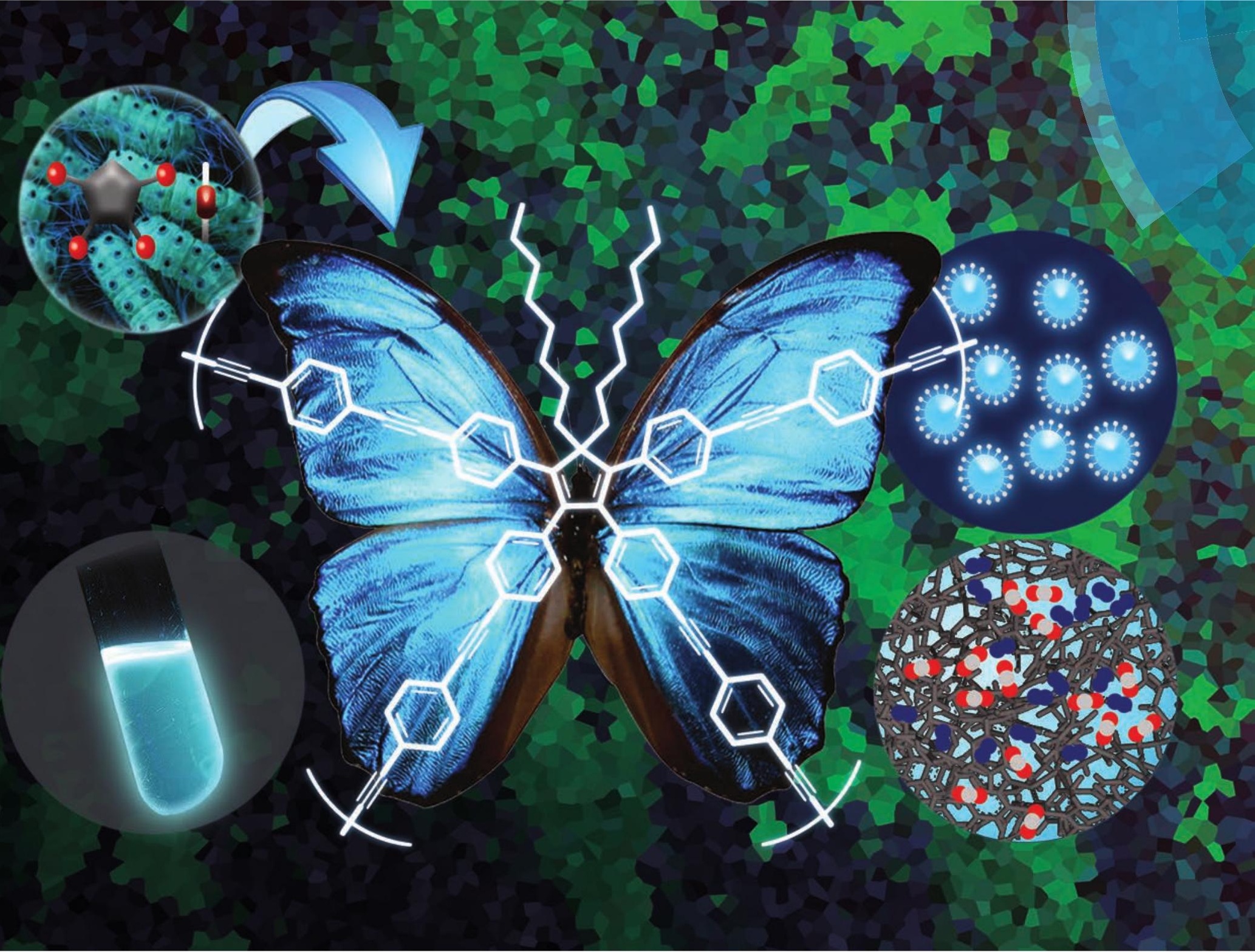

ISSN 1759-9954

Abhijit Patra et al.

Fabrication of porous organic polymers in the form of powder, soluble in organic solvents and nanoparticles: a unique platform for gas adsorption 


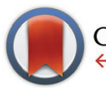

CrossMark \&lick for updates

Cite this: Polym. Chem., 2015, 6 , 3775

Received 12th February 2015, Accepted 7th April 2015

DOI: $10.1039 / c 5 p y 00235 d$

www.rsc.org/polymers

\title{
Fabrication of porous organic polymers in the form of powder, soluble in organic solvents and nanoparticles: a unique platform for gas adsorption and efficient chemosensing $\dagger$
}

\begin{abstract}
Sujoy Bandyopadhyay, Pragyan Pallavi, Amith G. Anil and Abhijit Patra*
Conjugated porous organic polymers based on a novel core of tetraphenyl-5,5-dioctylcyclopentadiene (TPDC) have been fabricated in the form of powder (P1), soluble in common organic solvents (P2) as well as aqueous dispersion of nanoparticles (P3). Fine tuning of the conditions of polycondensation reactions involving tetrakis(4-bromophenyl)-5,5-dioctylcyclopentadiene and diethynylbenzene leads to the formation of TPDC based polymers in three different forms. P1, P2 and P3 possess high thermal stability (up to $375^{\circ} \mathrm{C}$ ) and are porous in nature. The Brunauer-Emmett-Teller (BET) surface area and total pore volume of P1 were estimated to be $405 \mathrm{~m}^{2} \mathrm{~g}^{-1}$ and $0.68 \mathrm{~cm}^{3} \mathrm{~g}^{-1}$ respectively. Solid P1 was explored for hydrogen and carbon dioxide adsorption. Solution of $\mathbf{P} \mathbf{2}$ and aqueous dispersion of P3 exhibit strong cyan fluorescence and are applied for the sensing of nitroaromatics. Steady state and time resolved fluorescence measurements reveal the underlying photophysics of amplified fluorescence quenching of P2 and P3 by nitroaromatics. Porosity, gas adsorption, as well as solubility, strong fluorescence and sensing capabilities establish TPDC based porous polymers as new multifunctional materials and can find broad applications in sensing and optical devices.
\end{abstract}

\section{Introduction}

Porous organic polymers (POPs) have become an appealing field of research owing to their promising applications in various technological fields. ${ }^{1}$ POPs with high surface areas have been used mostly in gas storage, separation and heterogeneous catalysis. $^{2-4}$ Of late, combination of porosity and $\pi$-conjugation leads to the development of the field of conjugated microporous organic polymers (CMPs). ${ }^{5-10}$ Such $\pi$-conjugated porous materials possess immense potential in various optoelectronic and biological applications ranging from energy storage, ${ }^{7}$ tunable emission and light harvesting ${ }^{8}$ to chemo and biosensors. ${ }^{9}$ Recently mechanistic details on the origin of microporosity through the network forming Sonogashira cross coupling reactions have been demonstrated. ${ }^{10} \mathrm{Com}-$ putational methodologies have also been developed to

Department of Chemistry, Indian Institute of Science, Education and Research (IISER) Bhopal, Bhopal-462066, India. E-mail: abhijit@iiserb.ac.in;

Fax: +91 (o)755 409 2392; Tel: +91 (0)755 6692378

$\dagger$ Electronic supplementary information (ESI) available: Details of synthesis and characterization, fabrication of nanoparticles, microscopy, surface area analysis, computational and spectroscopic investigations and sensing studies. See DOI: 10.1039/c5py00235d understand the network structure in POPs as well as to predict the novel design principles. ${ }^{11}$

In spite of having interesting properties, poor solubility and hence difficulty in processability of POPs have posed a major bottleneck for their device integration and practical applications. ${ }^{12}$ Attempts were made to achieve desired solubility by fine tuning the structure and rigidity of macromolecular building blocks. ${ }^{13}$ By maintaining the microporous structure and $\pi$-conjugation, pyrene based soluble hyperbranched polymers and linear polymers have been synthesized. ${ }^{14}$ Preparation of solution dispersible POP nanoparticles is found to be another approach that has gained significant attention. ${ }^{15}$ However, the challenge remains to develop new multifunctional materials integrating the different properties like microporosity, gas adsorption in one hand and solubility, processability as well as strong fluorescence and sensing capabilities on the other hand. Fine tuning of covalent and non-covalent interactions and polymerization conditions can hold the key for the realization of the above mentioned theme.

Addressing the issue, herein we have developed soluble, conjugated and strongly fluorescent POPs employing a novel core of tetraphenyl-5,5-dioctylcyclopentadiene (TPDC). Fine tuning of the polymerization reactions involving tetrakis(4-bromophenyl)-5,5-dioctylcyclopentadiene (TBDC) and diethynylbenzene (DEB) as monomers allows us to obtain TPDC based 


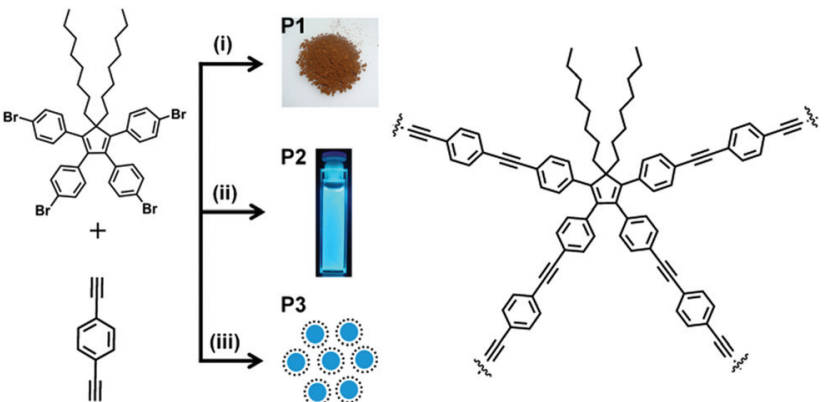

Scheme 1 Fabrication of porous organic polymers involving TBDC (tetrakis-(4-bromophenyl)-5,5-dioctylcyclopentadiene) and DEB (diethynylbenzene) in the form of powder (P1), soluble in organic solvents (P2) and aqueous dispersion of nanoparticles (P3). Fabrication conditions: (i) $\left[\mathrm{Pd}\left(\mathrm{PPh}_{3}\right)_{4}\right]$, Cul, diisopropylamine, toluene, $80{ }^{\circ} \mathrm{C}, 48 \mathrm{~h}$, (ii) $[\mathrm{Pd}-$ $\left.\left(\mathrm{PPh}_{3}\right)_{2} \mathrm{Cl}_{2}\right]$, Cul, diisopropylamine, toluene, $80{ }^{\circ} \mathrm{C}, 12 \mathrm{~h}$ and (iii) $[\mathrm{Pd}-$ $\left.\left(\mathrm{PPh}_{3}\right)_{4}\right], \mathrm{Cul}, \mathrm{SDS}$, water, diisopropylamine, toluene, $50^{\circ} \mathrm{C}, 48 \mathrm{~h}$.

POPs (Scheme 1) in the form of insoluble powder (P1), soluble in common organic solvents (P2) as well as aqueous dispersion of nanoparticles (P3). Surface area analysis coupled with molecular dynamics simulations, microscopic, steady state and time resolved spectroscopic investigations provide a unified picture of the network structure, physicochemical properties and efficient sensing capabilities of TPDC based POPs. Fabrication of cyclopentadiene based POPs in three different forms, solid, solution and nanoparticles starting from the same monomer and comonomer and exploration of their gas adsorption and sensing potential, to the best of our knowledge, have not been reported in the context of porous organic materials.

\section{Results and discussion}

TBDC was prepared from tetraphenylcyclopentadienone. Alkyl chains in TBDC impart flexibility in the resulting network. Fine tuning of concentration of a catalyst, time and temperature of $\left(\mathrm{A}_{4}+\mathrm{B}_{2}\right)$ type Sonogashira cross-coupling polycondensation led to the formation of P1, P2 and P3 (Scheme 1). Soluble polymers and nanoparticles were precipitated by adding toluene solution of $\mathbf{P 2}$ and water dispersion of P3 into excess of cold methanol respectively. The precipitated polymers were thoroughly washed by multiple Soxhlet extractions with different solvents. Finally, P2 and P3 obtained in the form of powders are soluble in common organic solvents like tetrahydrofuran, dichloromethane, chloroform, toluene and dimethylformamide.

The FTIR spectra of TPDC POPs (P1, P2, P3) show a characteristic band at $2200 \mathrm{~cm}^{-1}$ corresponding to $\mathrm{C} \equiv \mathrm{C}$ stretching indicating coupling between TBDC and DEB (Fig. S1-S3†). The signal at $89 \mathrm{ppm}$ in the ${ }^{13} \mathrm{C}$ NMR spectrum of $\mathbf{P} 2$ and $\mathbf{P 3}$ further confirms the presence of $\mathrm{C} \equiv \mathrm{C}$ (Fig. $\mathrm{S} 6 \dagger$ ). Thermogravimetric analysis (TGA) showed that all the polymers P1, P2 and

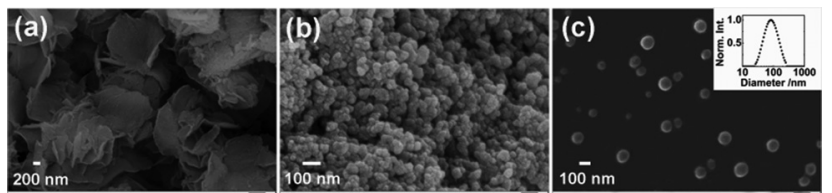

Fig. 1 FESEM images of (a) P1, (b) P2 and (c) P3; inset: DLS profile of aqueous dispersion of P3.
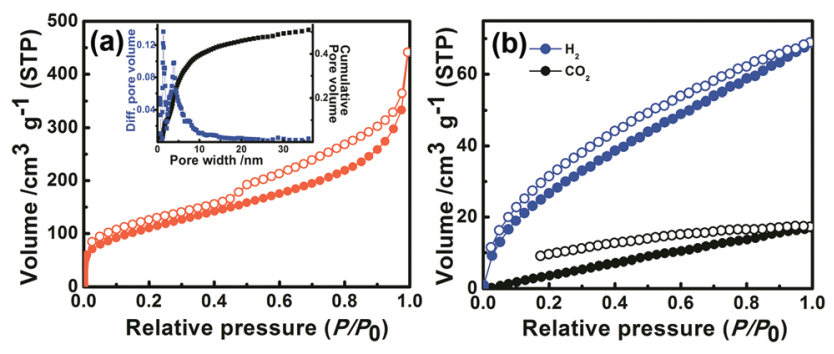

Fig. 2 (a) Nitrogen sorption isotherms (filled circles: adsorption; hollow circles: desorption) of P1 measured at $77 \mathrm{~K}$. Inset: pore-size distribution profiles estimated using the NLDFT method (blue squares: differential pore volume and black squares: cumulative pore volume). (b) Gas sorption isotherms of P1 for hydrogen (blue) at $77 \mathrm{~K}$ and carbon dioxide (black) at $298 \mathrm{~K}$ (filled circles: adsorption; hollow circles: desorption).

P3 are thermally stable up to $375^{\circ} \mathrm{C}$ (Fig. S7†). The weight average molecular weight $\left(M_{\mathrm{w}}\right)$ of $\mathbf{P 2}$ was found to be $16 \mathrm{kDa}$ with a polydispersity index of 1.2 , as measured by gel permeation chromatography (GPC). Field-emission scanning electron microscopy (FESEM) showed a plate like morphology for P1 (Fig. 1a). A rapidly precipitated powder of $\mathbf{P} 2$ was found to exhibit an aggregated sphere like morphology with an average diameter less than $100 \mathrm{~nm}$ (Fig. 1b). Aqueous dispersion of P3 revealed nanoparticles with a spherical morphology (Fig. 1c). The average diameter of the particles ranges from 70 to $110 \mathrm{~nm}$, as estimated by FESEM and corroborated with the profile obtained by dynamic light scattering (DLS) measurements (Fig. 1c, inset).

The nitrogen sorption profile of $\mathbf{P 1}$ at $77 \mathrm{~K}$ indicates type II isotherm (Fig. 2a). Gas uptake at low relative pressures $\left(P / P_{0}<\right.$ 0.1) signifies a microporous character. A large hysteresis loop observed at a relative pressure of $P / P_{0}=0.5$ indicates the existence of mesopores, originating probably due to interparticulate voids. ${ }^{7,14}$ The Brunauer-Emmett-Teller (BET) surface area and total pore volume of $\mathbf{P 1}$ were estimated to be $405 \mathrm{~m}^{2} \mathrm{~g}^{-1}$ and $0.68 \mathrm{~cm}^{3} \mathrm{~g}^{-1}$ respectively. Pore size distribution (Fig. 2a, inset) calculated by the nonlocal density functional theory (NLDFT) method revealed that the micropores are centered at $1.4 \mathrm{~nm}$, whereas mesopores range from 3 to $15 \mathrm{~nm}$. Hydrogen and carbon dioxide uptake of P1 (Fig. 2b) were estimated to be $68 \mathrm{~cm}^{3} \mathrm{~g}^{-1}\left(3.04 \mathrm{mmol} \mathrm{g}^{-1}\right.$ at $\left.1 \mathrm{bar}, 77 \mathrm{~K}\right)$ and $16 \mathrm{~cm}^{3} \mathrm{~g}^{-1}$ $\left(0.71 \mathrm{mmol} \mathrm{g}^{-1}\right.$ at $\left.1 \mathrm{bar}, 298 \mathrm{~K}\right)$ respectively. The nitrogen adsorption-desorption isotherms of $\mathbf{P 2}$ and $\mathbf{P} 3$ revealed a 


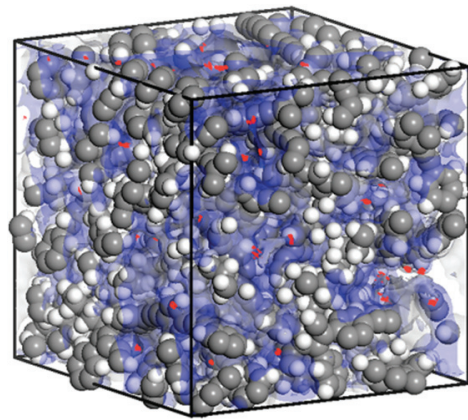

Fig. 3 Snapshot of nitrogen sorption in a simulated amorphous cell of TPDC based POPs at 1 bar and $77 \mathrm{~K}$ (red dots: density field of adsorbed nitrogen molecules; blue shades: solvent accessible surfaces).
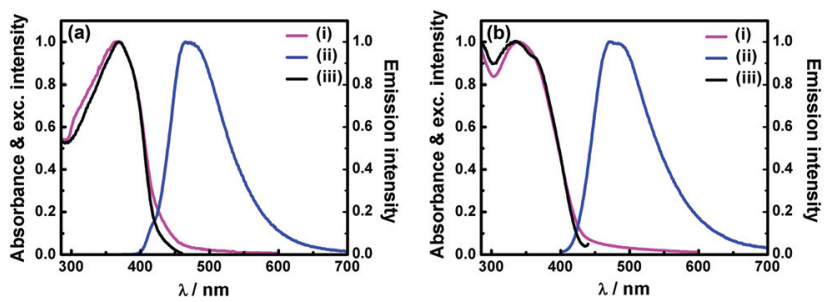

Fig. 4 (a) Spectroscopic features of P2 in THF: normalized (i) absorption, (ii) emission $\left(\lambda_{\mathrm{exc}}=365 \mathrm{~nm}\right)$, and (iii) excitation $\left(\lambda_{\mathrm{em}}=468 \mathrm{~nm}\right.$ ) spectra. (b) Spectroscopic features of aqueous dispersion of P3: normalized (i) absorption, (ii) emission $\left(\lambda_{\text {exc }}=340 \mathrm{~nm}\right)$, and (iii) excitation $\left(\lambda_{\mathrm{em}}=\right.$ $470 \mathrm{~nm}$ ) spectra.

porous nature with a BET surface area of $39 \mathrm{~m}^{2} \mathrm{~g}^{-1}$ and $143 \mathrm{~m}^{2} \mathrm{~g}^{-1}$ respectively (Fig. S11, Table S2 $\dagger$ ).

In order to gain an insight into the molecular level structure and to understand the porous nature of TPDC based polymers, an atomistic model was built and molecular dynamics simulations were carried out. ${ }^{11 a}$ Grand Canonical Monte Carlo (GCMC) simulations were performed at $77 \mathrm{~K}$ to obtain nitrogen sorption. ${ }^{11 b}$ The characteristics of the simulated model (Fig. 3) were found to be quite consistent with the experimental observations for P1. $\dagger$ The solvent accessible surface area and pore volume calculated using a probe radius of $1.82 \AA$ (the kinetic radius of $\mathrm{N}_{2}$ ) was found to be $345 \mathrm{~m}^{2} \mathrm{~g}^{-1}$ and $0.45 \mathrm{~cm}^{3} \mathrm{~g}^{-1}$ respectively (Fig. S12†).

Solid P1 does not show any detectable fluorescence. However, besides porous characters, the solution of $\mathbf{P 2}$ and aqueous dispersion of $\mathbf{P 3}$ were found to be strongly fluorescent. Electronic absorption and emission spectra of $\mathbf{P 2}$ in tetrahydrofuran (THF) show absorption with $\lambda_{\max }$ at $365 \mathrm{~nm}$ and strong fluorescence $\left(\Phi_{\mathrm{f}}=27 \%\right)$ with $\lambda_{\max }$ at $468 \mathrm{~nm}$ (Fig. 4a). Aqueous dispersion of P3 exhibits absorption with $\lambda_{\max }$ at $340 \mathrm{~nm}$ and emission $\left(\Phi_{\mathrm{f}}=8 \%\right)$ peaks at $470 \mathrm{~nm}$ (Fig. 4b). $\dagger$ The intense absorption band of TPDC POPs is assignable to the $\pi-\pi^{*}$ transition of the conjugated framework. Absorption and emission maxima of polymers (P2 and P3) were found to be red shifted compared to that of the TPDC core showing $\lambda_{\max }^{\text {abs }}$ at $326 \mathrm{~nm}$ and $\lambda_{\max }^{\mathrm{em}}$ at $427 \mathrm{~nm}$ (Fig. S15†). The observed red shift can be attributed to the three dimensional extended $\pi$-conjugated framework in polymers. ${ }^{9 a}$ The fluorescence excitation spectra of $\mathbf{P 2}$ and $\mathbf{P 3}$ (Fig. 4) are found to be very similar to the absorption spectra indicating that the emission is initiated by a vertical excitation process. The excited state dynamics were investigated using a time-correlated single-photon counting experiment. The weighted average lifetimes of $\mathbf{P} 2$ in THF and aqueous dispersion of $\mathbf{P 3}$ are found to be 0.94 and 0.68 ns respectively (Fig. S17, Table S3†).

Strong fluorescence and porosity in $\mathbf{P} 2$ and $\mathbf{P} 3$ prompted us to explore their potential in chemosensing. A range of electron deficient nitroaromatic compounds (NC) like nitrobenzene, $m$-dinitrobenzene, 2,4-dinitrotoluene and picric acid (PA) was chosen as electron deficient analytes. Upon successive addition of NC, the fluorescence intensity of THF solution of P2 and aqueous dispersion of P3 decreases gradually (Fig. 5a and $b$ and Fig. S19a-S24a). PA being the most electron deficient exhibits the best quenching efficiency. At PA concentrations of 1.33 and $0.23 \mathrm{mM}$ fluorescence signals of $\mathbf{P 2}$ and $\mathbf{P 3}$ were quenched by $93 \%$ and $98 \%$ respectively (Fig. $5 \mathrm{a}$ and b, inset). Further addition of PA led to complete quenching. Quenching of fluorescence of P3 can be observed at a PA concentration as low as $2 \mathrm{ppm}$ indicating high sensitivity. The Stern-Volmer plots bend upwards for $\mathbf{P 2}$ and $\mathbf{P} 3$ on increasing
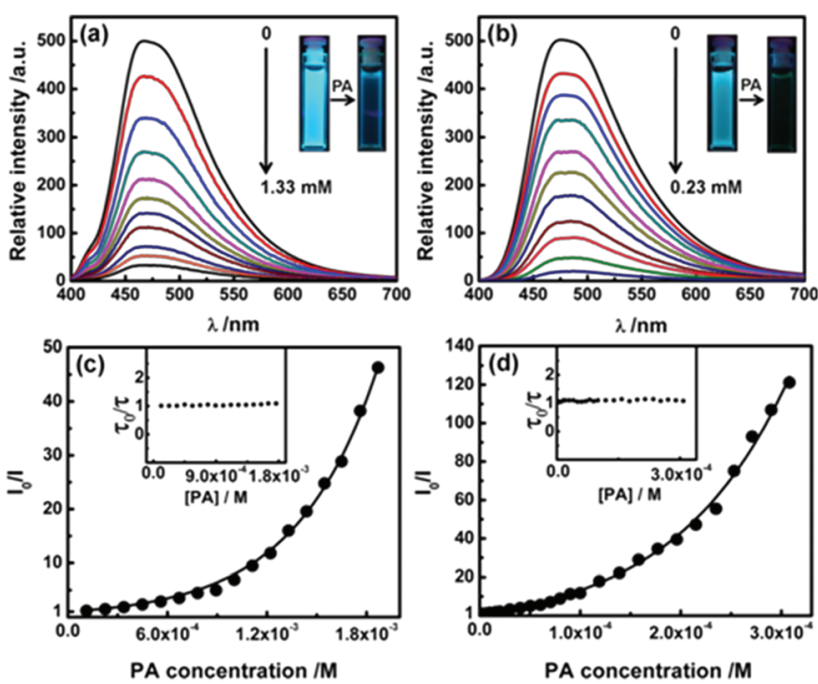

Fig. 5 (a) Emission spectra demonstrating the quenching of fluorescence of (a) P2 in THF $\left(\lambda_{\mathrm{ex}}=365 \mathrm{~nm}\right)$ and (b) P3 in water $\left(\lambda_{\mathrm{ex}}=\right.$ $340 \mathrm{~nm}$ ) with increasing concentrations of picric acid (PA). Inset: photographs of (a) P2 and (b) P3 before and after addition of PA under the illumination of UV light at $365 \mathrm{~nm}$. Stern-Volmer plots of $I_{0} / /$ against the concentration of PA $\left(I_{0}=\right.$ fluorescence intensity at $\left.[\mathrm{PA}]=0 \mathrm{M}\right)$ of (c) P2 in THF and (d) P3 in water; the inset graphs refer to plots of the corresponding relative fluorescence lifetime $\left(\tau_{0} / \tau\right)$ against various concentrations of PA ( $\tau_{0}=$ lifetime of a polymer in the absence of PA). 
concentration of NC suggesting an amplified quenching (Fig. 5c and d and Fig. S19b-S24b †) ${ }^{16}$ No significant decrease of average fluorescence lifetimes of $\mathbf{P 2}$ and $\mathbf{P} 3$ with increasing concentrations of $\mathrm{NC}$ indicates that the quenching process is likely to be static in nature (Fig. $5 \mathrm{c}$ and d, inset). ${ }^{17} \dagger$ Such amplified static quenching can be attributed to the loose ground state association of nitroaromatic molecules with the pores of $\mathbf{P} 2$ and $\mathbf{P} 3 .{ }^{18}$ Accordingly, a quenching sphere model was employed to fit the quenching data (Fig. $5 \mathrm{c}$ and $\mathrm{d}$ and Fig. S19b-S24b $\dagger$ ); the static quenching constants for $\mathbf{P 2}$ and $\mathbf{P 3}$ at lower concentrations of PA were found to be $2.1 \times 10^{3}$ and $7.6 \times 10^{4} \mathrm{~L} \mathrm{~mol}^{-1}$ respectively. ${ }^{17,18} \dagger$ The quenching efficiency of nitroaromatic compounds towards $\mathbf{P 2}$ and $\mathbf{P 3}$ was found to follow the order $\mathrm{NB}<\mathrm{DNB}<\mathrm{DNT}<\mathrm{PA}$, consistent with the trend reported earlier for other covalent organic polymers (Tables S6 and S7 $\dagger$ ). ${ }^{19}$ As indicated, nanoparticle dispersions (P3) exhibit enhanced quenching compared to that of isolated species in THF (P2). It is presumably due to the higher surface area and more accessible cavities leading to efficient interactions of nitroaromatic molecules with the nanoaggregates. ${ }^{16,18}$

\section{Conclusions}

A convenient protocol has been demonstrated to fabricate cyclopentadiene based porous organic polymers in three different forms: powder (P1), soluble in organic solvents (P2) and aqueous dispersion of nanoparticles (P3). Solid P1 was explored for hydrogen and carbon dioxide adsorption while soluble counterparts $\mathbf{P} 2$ and $\mathbf{P} 3$ demonstrate efficient sensing of picric acid by amplified fluorescence quenching. Currently, we are exploring the possibility of fluorescence tuning by attaching suitable acceptor dyes at the surface of nanoparticles. Preliminary exploration suggests facile energy transfer from nanoparticles P3 to surface-bound Rhodamine 6G molecules leading to the switching of emission towards longer wavelength regions (Fig. S26 $†$ ). The current study paves the way for the development of multifunctional materials based on porous organic polymers.

\section{Experimental}

\section{General methods}

All reagents and solvents were purchased from commercial sources and used without purification. ${ }^{1} \mathrm{H}$ and ${ }^{13} \mathrm{C}-\mathrm{NMR}$ spectra were recorded on Bruker Avance III 500, $700 \mathrm{MHz}$ NMR spectrometers. FTIR measurements were carried out on a Perkin Elmer FTIR spectrophotometer. Thermogravimetric analysis (TGA) was carried out using a Perkin Elmer TGA-6000 instrument. The samples were heated at a rate of $10{ }^{\circ} \mathrm{C} \mathrm{min}^{-1}$ under a nitrogen atmosphere to a maximum of $900^{\circ} \mathrm{C}$. Molecular weights of the soluble polymers were estimated by Gel Permeation Chromatography (GPC, Polymer Laboratories). THF was used as the eluent with a flow rate of $1 \mathrm{~mL} \mathrm{~min}{ }^{-1}$ at
$40{ }^{\circ} \mathrm{C}$ and polystyrene was used as the calibration standard. Universal calibration was used by employing refractive indexes and viscometry detectors. Ultrasonication was carried out with a Branson sonifier (model: W-450) using a microtip of $5 \mathrm{~mm}$ diameter.

The surface morphology of all polymers and size of the nanoparticles were examined using a Carl Zeiss (UltraPlus) field emission scanning electron microscope (FESEM). Energy dispersive X-ray spectroscopy was performed using a spectrometer (Oxford Instruments X-Max ${ }^{\mathrm{N}}$ ) attached to FESEM. Dynamic light scattering (DLS) measurements of aqueous dispersion of nanoparticles (P3) were carried out with a Beckman Coulter Delso Nano C DLS set up.

All gas adsorption experiments were performed on a Quantachrome Autosorb QUA211011 equipment. Nitrogen adsorption isotherms were analyzed using ASIQwin software. Samples were degassed at $80^{\circ} \mathrm{C}$ for $12 \mathrm{~h}$ under vacuum before analysis. Nitrogen and hydrogen adsorption-desorption isotherms were measured at $77 \mathrm{~K}$ and for carbon dioxide at 298 K. Polymer surface areas and pore size distributions were measured by using nitrogen adsorption-desorption isotherms. The total pore volume of $\mathbf{P 1}$ was estimated to be $0.68 \mathrm{~cm}^{3} \mathrm{~g}^{-1}$ according to single point adsorption at $P / P_{0}=0.99$. Pore size distributions were derived from the nonlocal density functional theory (NLDFT) method. The micropore surface area of P1 calculated from the $\mathrm{N}_{2}$ adsorption isotherm using the $t$-plot method based on the Halsey thickness equation was found to be $75 \mathrm{~m}^{2} \mathrm{~g}^{-1}$.

A molecular model of TPDC based polymers was built using the Materials Studio 6.1 package (Accelrys). The model structure of the polymer was constructed with a net molar mass of $16358 \mathrm{~g} \mathrm{~mol}^{-1}$. All molecular dynamics and energy minimization were performed with a Discover module using COMPASS force field. Multiple compression and decompression were carried out to equilibrate the amorphous cell. ${ }^{20}$ The Noose Hover thermostat during NVT steps and the Andersen barostat during NPT steps were used. The final density of the relaxed structure was $0.85 \mathrm{~g} \mathrm{~cm}^{-3}$. The adsorption isotherm of nitrogen was simulated at $77 \mathrm{~K}$ up to 1 bar using GCMC simulation. $\dagger$

UV-vis absorption spectra were recorded on a Cary 100 spectrophotometer. Steady state fluorescence measurements were carried out on a Jobin Yvon Horiba Model Fluorolog-3-21. The fluorescence quantum yields of $\mathbf{P} 2$ in THF and $\mathbf{P} 3$ in water were estimated by comparison with coumarin-102 in ethanol $\left(\Phi_{\mathrm{f}}=0.76\right)$ and corrected for the refractive index of the solvent. ${ }^{21}$ Time-resolved fluorescence measurements were carried out using a time-correlated single-photon counting (TCSPC) spectrometer (Delta Flex-01-DD/HORIBA). Delta diode laser at $370 \mathrm{~nm}$ with FWHM $=154$ ps was used as the excitation source. A picosecond photon detection module with a photomultiplier tube was used as the detector. Instrument response function was recorded by using an aqueous solution of Ludox. Decay curves were analyzed by nonlinear leastsquares iteration using IBH DAS6 (version 6.8) decay analysis software. 


\section{Synthesis of monomers}

Tetraphenylcyclopentadiene (TPCP). Tetraphenylcyclopentadiene (TPCP) was synthesized starting from tetraphenylcyclopentadienone following a reported procedure with minor modifications. ${ }^{22}$

${ }^{1} \mathrm{H}$ NMR: $\delta_{\mathrm{H}}\left(500 \mathrm{MHz}, \mathrm{CDCl}_{3}\right) 7.22-7.11(16 \mathrm{H}, \mathrm{m})$, 7.00-6.96 (4 H, m), $4.04(2 \mathrm{H}, \mathrm{s}) ;{ }^{13} \mathrm{C}$ NMR: $\delta_{\mathrm{C}}(126 \mathrm{MHz}$, $\left.\mathrm{CDCl}_{3}\right)$ 144.55, 139.75, 136.60, 136.48, 129.85, 128.15, 128.05, 127.84, 126.69, 126.40, 45.81; MS (MALDI-TOF): calculated for $\mathrm{C}_{29} \mathrm{H}_{22}, 370.48$; found 370.19 .

Tetraphenyl-5,5-dioctylcyclopentadiene (TPDC). TPCP (1 g, $2.69 \mathrm{mmol}$ ) and tetra- $n$-butylammonium bromide $(262 \mathrm{mg}$, $0.81 \mathrm{mmol}$ ) were dissolved in $5 \mathrm{~mL}$ DMSO. 1-Bromooctane (1 mL, $5.92 \mathrm{mmol}$ ) and $1.2 \mathrm{~mL} 50 \%$ aqueous $\mathrm{NaOH}$ were added to it. The reaction mixture was stirred at $80-90{ }^{\circ} \mathrm{C}$ for 2 h. After cooling down to room temperature, the reaction mixture was poured into $100 \mathrm{~mL}$ of water and then extracted three times with chloroform. The organic layer was washed with water and brine solution, and dried over $\mathrm{MgSO}_{4}$. After evaporation of the solvent the resulting residue was purified via column chromatography $\left(\mathrm{SiO}_{2}\right.$, hexane) and a colorless oil was obtained. The liquid was dissolved in ethanol and recrystallized to obtain the pure compound as a colorless solid (0.803 g, 50\% yield).

${ }^{1} \mathrm{H}$ NMR: $\delta_{\mathrm{H}}\left(500 \mathrm{MHz}, \mathrm{CDCl}_{3}\right) 7.21(4 \mathrm{H}, \mathrm{t}, J 7.5), 7.17(2 \mathrm{H}$, d, J 7.1), 7.07 (4 H, d, J 7.8), 7.06-7.01 (6 H, m), $6.82(4 \mathrm{H}, \mathrm{d}$, $J ~ 7.4), 1.73-1.71(4 \mathrm{H}, \mathrm{m}), 1.32-1.04(24 \mathrm{H}, \mathrm{m}), 0.85(6 \mathrm{H}, \mathrm{t}$, $J$ 7.1); ${ }^{13} \mathrm{C}$ NMR: $\delta_{\mathrm{C}}\left(126 \mathrm{MHz}, \mathrm{CDCl}_{3}\right) 147.75,144.06,137.14$, 136.17, 130.31, 129.71, 127.93, 127.36, 126.37, 126.06, 64.57, $35.48,31.84,29.77,29.38,29.23,23.17,22.66,14.12$; MS (MALDI-TOF): calculated for $\mathrm{C}_{45} \mathrm{H}_{54}, 594.91$; found 594.37 .

Tetrakis(4-bromophenyl)-5,5-dioctylcyclopentadiene (TBDC). TPDC (350 mg, $0.59 \mathrm{mmol}$ ) was dissolved in $5 \mathrm{~mL} \mathrm{CHCl}_{3}$, then bromine $(0.36 \mathrm{~mL}, 7.05 \mathrm{mmol})$ was added to it. The reaction mixture was stirred at room temperature for $10 \mathrm{~h}$ under protection from light. Then the reaction mixture was poured into $50 \mathrm{~mL}$ chloroform and washed three times with sodium thiosulfate solution $(1 \mathrm{M})$ and dried over $\mathrm{MgSO}_{4}$. After the evaporation of the solvent the residue was purified via column chromatography ( $\mathrm{SiO}_{2}$, hexane) to obtain a colorless oil. The liquid was dissolved in ethanol and recrystallized to obtain the pure compound as a colorless solid (350 mg, 65\% yield).

${ }^{1} \mathrm{H}$ NMR: $\delta_{\mathrm{H}}\left(500 \mathrm{MHz}, \mathrm{CDCl}_{3}\right) 7.36(4 \mathrm{H}, \mathrm{d}, J 8.5), 7.20(4 \mathrm{H}$, d, $J$ 8.5), 6.88 (4 H, d, $J$ 8.5), $6.64(4 \mathrm{H}, \mathrm{d}, J 8.5), 1.69-1.66(4 \mathrm{H}$, $\mathrm{m}), 1.26-1.04(24 \mathrm{H}, \mathrm{m}), 0.86(6 \mathrm{H}, \mathrm{t}, J 7.1) ;{ }^{13} \mathrm{C} \mathrm{NMR} \delta_{\mathrm{C}}$ (126 $\mathrm{MHz}, \mathrm{CDCl}_{3}$ ) 147.74, 142.95, 135.18, 134.11, 131.72, 131.52, 131.07, 131.06, 121.05, 120.86, 64.80, 35.35, 31.80, 29.62, 29.30, 29.18, 23.16, 22.64, 14.11; MS (MALDI-TOF): calculated for $\mathrm{C}_{45} \mathrm{H}_{50} \mathrm{Br}_{4}, 910.49$; found 910.04.

\section{Fabrication of polymers in different forms}

Synthesis of a polymer in the form of powder (P1). TBDC (183 mg, $0.2 \mathrm{mmol}$ ), 1,4-diethynylbenzene (DEB) (76 mg, $0.6 \mathrm{mmol})$, copper(I) iodide $(1.9 \mathrm{mg}, 0.01 \mathrm{mmol})$ and tetrakis (triphenylphosphine)palladium $(23 \mathrm{mg}, 0.02 \mathrm{mmol}$ ) were dis- solved in $10 \mathrm{~mL}$ dry toluene and subjected to three freezepump-thaw cycles to remove the dissolved oxygen. Then $10 \mathrm{~mL}$ of freshly distilled diisopropylamine was added to it and again the reaction mixture was degassed by three freezepump-thaw cycles. The reaction mixture was stirred for $48 \mathrm{~h}$ at $80{ }^{\circ} \mathrm{C}$ under an argon atmosphere and under protection from light. The reaction mixture was brought to room temperature and the precipitate was collected through gravimetric filtration. The precipitate washed with methanol, acetone and chloroform was then rigorously washed by Soxhlet extraction for $24 \mathrm{~h}$ each with methanol, acetone, chloroform and ethanol respectively and dried under vacuum at $70{ }^{\circ} \mathrm{C}$ to give polymer P1 (92 mg, 49\% yield) as a brown solid.

FTIR $\left(\nu_{\max } / \mathrm{cm}^{-1}\right)$ : 3037, 2926, 2852, 2202, 1596, 1489, 829; EDX analysis (wt\%): C 98.74, Br 0.74, Pd 0.53.

Synthesis of soluble polymer (P2). TBDC ( $91 \mathrm{mg}, 0.1 \mathrm{mmol}$ ), 1,4-diethynylbenzene (DEB, $25 \mathrm{mg}, 0.2 \mathrm{mmol}$ ), copper(I) iodide (1.3 $\mathrm{mg} 0.007 \mathrm{mmol}$ ), and bis(triphenylphosphine)palladium (II) dichloride (10.5 mg, $0.015 \mathrm{mmol}$ ) were dissolved in $20 \mathrm{~mL}$ degassed toluene. $20 \mathrm{~mL}$ of freshly distilled diisopropylamine was added to it. The reaction mixture was stirred for $12 \mathrm{~h}$ at $80^{\circ} \mathrm{C}$ under an argon atmosphere under protection from light. Then the reaction mixture was cooled to room temperature and filtered. The filtrate was precipitated in cold methanol and the precipitate was thoroughly washed with methanol, acetone and then rigorously washed by Soxhlet extraction for $24 \mathrm{~h}$ each with methanol and acetone respectively and dried under vacuum at $70{ }^{\circ} \mathrm{C}$ to give the pure polymer P2 (38 mg, 45\% yield) as a yellow solid.

GPC (THF): $\left(M_{\mathrm{n}}=13 \mathrm{kDa}, M_{\mathrm{w}}=16 \mathrm{kDa}\right) ;$ FTIR $\left(\nu_{\max } / \mathrm{cm}^{-1}\right)$ : 3035， 2925，2850， 2205，1595， 1485，830; ${ }^{1} \mathrm{H}$ NMR: $\delta_{\mathrm{H}}$ (700 MHz; $\mathrm{CDCl}_{3}$ ) 7.50-7.47 (m, Ar-H), 7.43-7.31 (m, Ar-H), 7.20 (br, Ar-H), 7.01 (br, Ar-H), 6.90 (b, Ar-H), 6.77 (br, Ar-H), 6.66 (br, Ar-H), $1.71\left(\mathrm{~m}, \mathrm{CH}_{2}\right), 1.34-1.07\left(\mathrm{br}, \mathrm{CH}_{2}\right), 0.86(\mathrm{t}$, $\mathrm{CH}_{3}$ ); EDX analysis (wt\%): C 98.51, $\mathrm{Br} 1.07$, Pd 0.42 .

Fabrication of nanoparticles (P3) by miniemulsion polymerization. $500 \mathrm{mg}$ of sodium dodecyl sulfate (SDS) was dissolved in $50 \mathrm{~mL}$ of degassed water. Dry toluene $(1.1 \mathrm{~mL})$ and freshly distilled diisopropylamine $(0.7 \mathrm{~mL})$ were added to a mixture of TBDC (91 mg, $0.1 \mathrm{mmol}$ ), 1,4-diethynylbenzene (DEB, $38 \mathrm{mg}, 0.30 \mathrm{mmol}$ ), tetrakis(triphenylphosphine)palladium (8 mg, $0.007 \mathrm{mmol}$ ) and copper(I) iodide $(0.6 \mathrm{mg}$, $0.0035 \mathrm{mmol})$. Then the mixture was added to a surfactant solution while stirring (1200 rpm). After stirring vigorously for $5 \mathrm{~min}$ for pre-emulsification, the mixture was ultrasonicated for 2 min under argon flow to obtain a stable miniemulsion. Gentle stirring of the miniemulsion at $50{ }^{\circ} \mathrm{C}$ under an $\mathrm{Ar}$ atmosphere for $48 \mathrm{~h}$ formed a stable colloidal dispersion. This dispersion was stirred, open to air for $24 \mathrm{~h}$ and filtered over a sintered glass crucible.

An aliquot of nanoparticle dispersion was precipitated by addition to excess of cold methanol and collected after washing with water, methanol and acetone, and then rigorously washed by Soxhlet extraction for $24 \mathrm{~h}$ each with methanol and acetone respectively. It was then dried under vacuum at $70^{\circ} \mathrm{C}$ and was used for FTIR and NMR characterization. 
FTIR $\left(\nu_{\max } / \mathrm{cm}^{-1}\right)$ 3042, 2928, 2854, 2212, 1592, 1484, 834; ${ }^{1} \mathrm{H}$ NMR: $\delta_{\mathrm{H}}\left(700 \mathrm{MHz} ; \mathrm{CDCl}_{3}\right) 7.50-7.47(\mathrm{~m}, \mathrm{Ar}-\mathrm{H}), 7.43-7.34$ (m, Ar-H), 7.20 (br, Ar-H), 7.01 (br, Ar-H), 6.89 (br, Ar-H), 6.77 (br, Ar-H), 6.70-6.63 (br, Ar-H), 1.71 (m, $\mathrm{CH}_{2}$ ), 1.31-1.09 (br, $\left.\mathrm{CH}_{2}\right), 0.86\left(\mathrm{t}, \mathrm{CH}_{3}\right)$.

\section{Acknowledgements}

Financial support from DST (SB/FT/CS-081/2013), New Delhi and infrastructural support from IISER Bhopal are gratefully acknowledged. SB thanks IISERB and PP thanks UGC for fellowship.

\section{Notes and references}

1 (a) J. Germain, J. M. J. Fréchet and F. Svec, Small, 2009, 5, 1098; (b) A. Thomas, Angew. Chem., Int. Ed., 2010, 49, 8328; (c) R. Dawson, A. I. Cooper and D. J. Adams, Prog. Polym. Sci., 2012, 37, 530; (d) D. Wu, F. Xu, B. Sun, R. Fu, H. He and K. Matyjaszewski, Chem. Rev., 2012, 112, 3959.

2 (a) T. Ben, H. Ren, S. Ma, D. Cao, J. Lan, X. Jing, W. Wang, J. Xu, F. Deng, J. M. Simmons, S. Qiu and G. Zhu, Angew. Chem., Int. Ed., 2009, 48, 9457; (b) D. Yuan, W. Lu, D. Zhao and H. C. Zhou, Adv. Mater., 2011, 23, 3723.

3 (a) E. Preis, C. Widling, U. Scherf, S. Patil, G. Brunklaus, J. Schmidt and A. Thomas, Polym. Chem., 2011, 2, 2186; (b) Q. Chen, M. Luo, P. Hammershøj, D. Zhou, Y. Han, B. W. Laursen, C. G. Yan and B. H. Han, J. Am. Chem. Soc., 2012, 134, 6084; (c) S. Chakraborty, Y. J. Colón, R. Q. Snurr and S. T. Nguyen, Chem. Sci., 2015, 6, 384.

4 (a) Q. Liang, J. Liu, Y. Wei, Z. Zhao and M. J. MacLachlan, Chem. Commun., 2013, 49, 8928; (b) R. K. Totten, Y. S. Kim, M. H. Weston, O. K. Farha, J. T. Hupp and S. T. Nguyen, J. Am. Chem. Soc., 2013, 135, 11720.

5 (a) A. I. Cooper, Adv. Mater., 2009, 21, 1291; (b) F. Vilela, K. Zhang and M. Antonietti, Energy Environ. Sci., 2012, 5, 7819; (c) Y. Xu, S. Jin, H. Xu, A. Nagai and D. Jiang, Chem. Soc. Rev., 2013, 42, 8012.

6 (a) K. V. Rao, S. Mohapatra, T. K. Maji and S. J. George, Chem. - Eur. J., 2012, 18, 4505; (b) K. Zhang, D. Kopetzki, P. H. Seeberger, M. Antonietti and F. Vilela, Angew. Chem., Int. Ed., 2013, 52, 1432; (c) Y. Xie, T. T. Wang, X. H. Liu, K. Zou and W. Q. Deng, Nat. Commun., 2013, 4, 1960; (d) H. Bildirir, J. P. Paraknowitsch and A. Thomas, Chem. Eur. J., 2014, 20, 9543; (e) Y. Liao, J. Weber and C. F. J. Faul, Chem. Commun., 2014, 50, 8002.

7 F. Xu, X. Chen, Z. Tang, D. Wu, R. Fu and D. Jiang, Chem. Commun., 2014, 50, 4788.
8 L. Chen, Y. Honsho, S. Seki and D. Jiang, J. Am. Chem. Soc., 2010, 132, 6742.

9 (a) Y. Zhang, S. A. Y. Zou, X. Luo, Z. Li, H. Xia, X. Liu and Y. $\mathrm{Mu}, J$. Mater. Chem. A, 2014, 2, 13422; (b) C. Gu, N. Huang, J. Gao, F. Xu, Y. Xu and D. Jiang, Angew. Chem., Int. Ed., 2014, 53, 4850.

10 A. Laybourn, R. Dawson, R. Clowes, T. Hasell, A. I. Cooper, Y. Z. Khimyak and D. J. Adams, Polym. Chem., 2014, 5, 6325.

11 (a) J. X. Jiang, F. Su, A. Trewin, C. D. Wood, H. Niu, J. T. A. Jones, Y. Z. Khimyak and A. I. Cooper, J. Am. Chem. Soc., 2008, 130, 7710; (b) L. J. Abbott and C. M. Colina, Macromolecules, 2011, 44, 4511.

12 A. Patra and U. Scherf, Chem. - Eur. J., 2012, 18, 10074.

13 (a) N. B. McKeown and P. M. Budd, Chem. Soc. Rev., 2006, 35, 675; (b) N. B. McKeown and P. M. Budd, Macromolecules, 2010, 43, 5163.

14 (a) G. Cheng, T. Hasell, A. Trewin, D. J. Adams and A. I. Cooper, Angew. Chem., Int. Ed., 2012, 51, 12727; (b) G. Cheng, B. Bonillo, R. S. Sprick, D. J. Adams, T. Hasell and A. I. Cooper, Adv. Funct. Mater., 2014, 24, 5219.

15 (a) A. Patra, J. M. Koenen and U. Scherf, Chem. Commun., 2011, 47, 9612; (b) M. G. Schwab, D. Crespy, X. Feng, K. Landfester and K. Müllen, Macromol. Rapid Commun., 2011, 32, 1798; (c) K. Wu, J. Guo and C. Wang, Chem. Commun., 2014, 50, 695; (d) X. Wu, H. Li, Y. Xu, B. Xu, H. Tong and L. Wang, Nanoscale, 2014, 6, 2375.

16 (a) C. Y. K. Chan, Z. Zhao, J. W. Y. Lam, J. Liu, S. Chen, P. Lu, F. Mahtab, X. Chen, H. H. Y. Sung, H. S. Kwok, Y. Ma, I. D. Williams, K. S. Wong and B. Z. Tang, Adv. Funct. Mater., 2012, 22, 378; (b) W. Dong, T. Fei, A. PalmaCando and U. Scherf, Polym. Chem., 2014, 5, 4048.

17 J. R. Lakowicz, Principles of Fluorescence Spectroscopy, Springer, New York, 2006.

18 Y. Zhang, G. Chen, Y. Lin, L. Zhao, W. Z. Yuan, P. Lu, C. K. W. Jim, Y. Zhang and B. Z. Tang, Polym. Chem., 2015, 6, 97.

19 Z. Xiang and D. Cao, Macromol. Rapid Commun., 2012, 33, 1184.

20 L. J. Abbott, A. G. McDermott, A. D. Regno, R. G. D. Taylor, C. G. Bezzu, K. J. Msayib, N. B. McKeown, F. R. Siperstein, J. Runt and C. M. Colina, J. Phys. Chem. B, 2013, 117, 355.

21 (a) K. Rurak and M. Spieles, Anal. Chem., 2011, 83, 1232; (b) C. Wurth, M. Grabolle, J. Pauli, M. Spieles and U. R. Genger, Nat. Protoc., 2013, 8, 1535.

22 M. P. Castellani, J. M. Wright, S. J. Geib, A. L. Rheingold and W. C. Trogler, Organometallics, 1986, 5, 1116. 